\title{
Identidades Urbanas: desafios à etnografia na cidade
}

\section{Fernando Lucas Garcia de Souza*}

fernandogarcia.historia@gmail.com

\section{Resumo}

Este ensaio busca refletir sobre os desafios no trabalho de campo da chamada Antropologia Urbana, procurando dialogar com autores que problematizem a formação das identidades nas sociedades complexas da modernidade ou pósmodernidade, tentando, por meio da tatuagem, refletir sobre a complexidade dessas formações de identidades. Intentamos também uma aproximação entre a Antropologia e a História ao tratar o tema, à medida que pensamos ser frutífera a inserção de uma perspectiva diacrônica à análise sincrônica que comumente os antropólogos têm empregado ao pensar a tatuagem.

\section{Palavras-chave}

Etnografia urbana; Cidade; Tatuagem

\begin{abstract}
This essay intends to think about the challenges in the fieldwork of the Urban Anthropology, trying to dialogue with authors who problematize the identities formation in complex modern or post-modern societies, seeking, trough the tattoo, reflect about the identities formation complexities. We also intends an approach between the History and Anthropology, considering important to insert a diachronic perspective in the synchronic analysis that the anthropologists usually use to think the tattoo problem.
\end{abstract}

\section{Keywords}

Urban ethnography; City; Tattoo 
A Antropologia é uma ciência que nasceu (do) e se desenvolve (no) contato com "o outro", na tentativa de compreensão deste "outro". Diante desse desafio de compreender indivíduos e sociedades tão diversas, sua organização, suas relações sociais e de parentesco, suas tecnologias, seus rituais e relações com a subjetividade, seus hábitos e costumes, a Antropologia comumente adota um conceito: cultura. Como aponta Roy Wagner, o conceito de cultura é tão associado ao pensamento antropológico que "poderíamos definir um Antropólogo como alguém que usa a palavra 'cultura' habitualmente"(WAGNER, 2010, p.27). Para Marshall Sahlins, o termo cultura é tão fundamental, que abandoná-lo traria como consequência o risco de perder a compreensão do fenômeno que esse termo define: "a organização da experiência e da ação humanas por meios simbólicos" (SAHLINS, 1997, p.41). Desse modo, considerando a Antropologia uma ciência que se ocupa da compreensão do Homem por meio da cultura, pretendemos neste ensaio, discutir a respeito desta tarefa no contexto das cidades, centrando, portanto, a discussão na chamada Antropologia Urbana.

\section{A Antropologia nas cidades: novos sujeitos}

Referenciando Lévi-Strauss e sua obra $O$ pensamento selvagem ${ }^{1}$, diria que, nos estudos da Antropologia Urbana, a selva é outra. O campo de pesquisa do antropólogo urbano é a "selva de pedra". Por mais poética e/ou clichê que a sentença possa parecer, é interes- sante que nos debrucemos sobre ela por um momento a fim de refletirmos algumas concepções antropológicas. Não é necessário que retome aqui toda discussão acerca da história da Antropologia e seu desenvolvimento enquanto ciência, nomes como Laplantine já o fizeram de maneira que minhas limitações teóricas não me permitiriam fazê- $-1 \mathrm{o}^{2}$. O ponto a que me atenho, e justamente tomando Laplantine como referência, é a discussão que esse autor faz sobre a transformação da ciência Antropologia, enquanto seu objeto de pesquisa vai transformando-se. Para ele, o "primitivo" - objeto central de estudo da Antropologia em seu nascimento, uma vez que essa ciência se desenvolve a partir do encontro do ocidental com "o outro", ou seja, povos que mantinham diferentes culturas- lentamente desaparecerem em curso da história, na velocidade em que a colonização e a globalização alcançam seus locais de origem. Nesse mesmo sentido, escreve Sahlins:

\begin{abstract}
A antropologia é talvez a única disciplina fundada no princípio da coruja de Minerva: ela começou como uma disciplina profissional justamente quando seu objeto de estudo já ia desaparecendo. Mesmo se nem todos os assim chamados povos primitivos estavam fisicamente morrendo, suas culturas exóticas estavam certamente se desintegrando (por "aculturação”) sob o assédio da ordem capitalista mundial. Parecia que logo nada mais restaria a contemplar senão versões locais da “civilização” ocidental. (SAHLINS, 1997, p.2)
\end{abstract}

Uma vez que esse "primitivo" tende a desaparecer enquanto objeto de pesquisa antropológica - encontrar culturas que não sofreram o impacto da chamada

\footnotetext{
${ }^{1}$ É fundamental aqui salientar que utilizo o termo metaforicamente. O próprio Lévi-Strauss na obra citada discute brilhantemente a elaboração do pensamento nas sociedades tradicionais ou "selvagens/primitivas"e a forma como elas organizam sua racionalidade por meio dos mesmos recursos cognitivos que o pensamento científico. Como bem analisa Eduardo Viveiros de Castro: "O "pensamento selvagem" não é o pensamento dos "selvagens" ou dos "primitivos" (em oposição ao "pensamento ocidental"), mas o pensamento em estado selvagem, isto é, o pensamento humano em seu livre exercício, um exercício ainda não-domesticado em vista da obtenção de um rendimento. O pensamento selvagem não se opõe ao pensamento científico como duas formas ou duas lógicas mutuamente exclusivas. Sua relação é, antes, uma relação entre gênero (o pensamento selvagem) e espécie (o pensamento científico). Ambas as formas de pensamento se utilizam dos mesmos recursos cognitivos; o que as distingue é, diz Lévi-Strauss, o nível do real ao qual eles se aplicam: o nível das propriedades sensíveis (caso do pensamento selvagem), e o nível das propriedades abstratas (caso do pensamento científico) ". (VIVEIROS DE CASTRO, 2011)

${ }^{2}$ François Laplantine, em sua obra A prender Antropologia (2003), oferece uma elaborada e didática discussão acerca da história da Antropologia e sua formação enquanto ciência.
} 
globalização é cada vez mais raro, embora Sahlins coerentemente chame a atenção para a resistência e para como essas culturas têm ressignificado objetos ocidentais dentro de sua própria cultura ou até utilizado o termo "cultura" para resistir ${ }^{3}$ - a Antropologia se volta para outras figuras de "outros". Na proposta de Laplantine, esse "outro" poderia ser num primeiro momento a figura do camponês, ou de forma mais complexa, ele propunha a desvinculação de um objeto de estudos, não mais limitado "a um espaço geográfico, cultural ou histórico particular". Antes, propunha o que ele chama de estudo do homem inteiro, do homem em todas as sociedades, em qualquer local, em todos os estados e em todas as épocas.

É sob a perspectiva desses novos objetos que a chamada Antropologia Urbana se desenvolve. Mas ainda assim, o que seria, de fato, uma Antropologia Urbana? Apenas uma prática etnográfica realizada na cidade? Quem nos ajuda a pensar esta questão é Magnani.

\section{Em Antropologia Urbana e os desafios da me-}

trópole, o autor nos oferece uma definição bastante sintetizada - mas não por isso carente de profundidade reflexiva - acerca do tema. Magnani aponta que é recorrente a ideia de que a antropologia "recorta sempre, como tema de estudo, um objeto exótico, distante ou singularizado" (MAGNANI, 2003, p.1). Segundo ele, porém, essa questão é parte de um senso comum enganoso acerca dos "limites" da Antropologia. Pelo contrário, o autor propõe a Antropologia como um útil instrumento para compreensão dos fenômenos urbanos, especialmente aqueles ligados à dinâmica cultural e às formas de sociabilidade nas grandes cidades contemporâneas. (MAGNANI, 2003, p.3)

Para tal empreendimento, Magnani cita que uma das ferramentas metodológicas fundamentais é a etno- grafia. Sua conceituação do que é a etnografia inicia-se com uma útil descrição do que ela não é.

\begin{abstract}
Inicialmente, cabe mostrar o que ele não é, e, nesse campo, não são poucos os malentendidos: às vezes, é confundido com o detalhismo, com abusca obsessiva dos pormenores na descrição das situações de campo; emoutras, é identificado com a atitude de vestir a camisa ou ser o porta-voz dapopulação estudada, sobretudo quando esta é caracterizada como grupo excluídoou uma minoria; em algumas ocasiões, é identificado com a reproduçãodo discurso nativo, por meio da transcrição de trechos de entrevistas nos quais, para melhor efeito de verossimilhança, são cuidadosamente preservadosalguns erros de concordância ou sintaxe. Finalmente, para citar mais alguns desvios, o método etnográfico é visto como um esforço em transmitiro ponto de vista do nativo em sua autenticidade não contaminada com visões externas, ou ainda é identificado com o trabalho de campo em geral oucomo o conjunto das técnicas e métodos para fazer a pesquisa. (MAGNANI, 2003 p. 3)
\end{abstract}

Longas ressalvas feitas, Magnani termina por definir a etnografia como

\begin{abstract}
Uma forma especial de operar em que o pesquisador entra em contato com o universo dos pesquisados e compartilha seu horizonte, não para permanecer lá ou mesmo para captar e descrever a lógica de suas representações e visão de mundo, mas para, numa relação de troca, comparar suas próprias representações e teorias com as deles e assim tentar sair com um modelo novo de entendimento ou, ao menos, com uma pista nova, não prevista anteriormente. (MAGNANI, 2003, p. 4-5)
\end{abstract}

Entendendo com o autor que a Antropologia Urbana é uma útil ferramenta de análise social, que opera a partir da etnografia, sigamos retomando a frase que dá início a este capítulo, nosso "outro", objeto de estudo da Antropologia Urbana, é o indivíduo que vive e interage nas cidades, como o próprio termo sugere. $\mathrm{E}$ que, não nos enganemos, nossa "selva de pedra" pode ser o reduto de tantas "excentricidades", quanto as que

\footnotetext{
${ }^{3}$ No artigo citado, Sahlins defende que a cultura não desaparecerá como objeto da Antropologia, uma vez que a mesma tem sido utilizada pelos povos tradicionais para reivindicar direitos, reafirmar tradições e resistir. Em consonância com esta posição, ler Cunha (2014).
} 
intrigaram os primeiros etnógrafos que se arriscaram longe de casa. A cidade, inegável catalisadora de relações culturais as mais diversas, de encontros, tensões e arranjos entre diferentes sujeitos e grupos, contrariando a ideia de um ambiente padronizador de identidades, é um ambiente onde traços diacríticos tendem a ser realçados, proposição que se sustenta tanto na observação de Stuart Hall (2014), de que, na diáspora, os traços culturais tendem a ser reforçados, quanto na de Manuela Carneiro da Cunha (2014) a respeito da etnicidade como empecilho à formação das nações modernas:

A cultura, como complexo de Édipo e outros pecados originais, teria de ser redimida. E acreditava-se na benéfica influência das cidades, onde a vida seria regida por laços principalmente contratuais. Até que se descobriu que não só o chamado "tribalismo" não desaparecia nas cidades modernas africanas, como, ao contrário, ele se exacerbava. Em outras palavras, longe de proceder em Roma como os romanos, nunca se era tão apegado às tradições culturais quanto na diáspora. (CARNEIRO DA CUNHA, 2014 p.236)

Ainda localizando a cidade neste ambiente de troca - no sentido que Mauss (2013) atribui ao termo como "o processo de dar, receber e retribuir" - julgo ser interessante trazer ao diálogo a discussão de Barth (2000) sobre as fronteiras: situação em que grupos étnicos diferentes se encontram, estabelecendo relações, negociando tensões e mediando conflitos de identidade que surgem desses encontros. Nesse ambiente, onde as citadas trocas de Mauss se dão também no campo das identidades, para muito além das relações de produção e consumo de bens materiais e serviços, realizando-se no campo das fronteiras de que fala Barth, não é incomum encontrar indivíduos e grupos que, atravessando essas fronteiras, adotam traços culturais de outros grupos étnicos e/ou sociais.
A propósito, cabe a ressalva, referir-nos-emos a partir daqui a grupos sociais ao invés de grupos étnicos, como o faz Barth, por pensar que, sendo meu objeto de pesquisa a tatuagem contemporânea/urbana e aceitando a globalização como fenômeno presente nas cidades brasileiras, os grupos que pesquisamos tendem a ser heterogêneos no que diz respeito às características que Barth elenca ao definir grupos étnicos, sobretudo as de caráter biológico.

De forma alguma, intento dizer que os grupos étnicos tenham desaparecido na complexidade de relações das cidades, ou que sua análise não seja essencial, os recentes fluxos migratórios de haitianos, por exemplo, apontam não só a presença e organização dos grupos étnicos, da forma que os descreve Barth, nos contextos urbanos brasileiros, como a possibilidade do desenvolvimento de estudos antropológicos que nos permitam a compreensão das fronteiras de que fala o autor. Apenas apontamos aqui, ao tratar de grupos sociais, que aqueles não constituem nosso objeto específico de estudo, que nos atemos aos grupos mais heterogêneos que adotam outros tipos de sinais diacríticos, como aqueles a quem Maffesoli chamou tribos urbanas, definidas por ele como:

Diversas redes, grupos de afinidades e de interesse, laços de vizinhança que estruturam nossas megalópoles. Seja ele qual for, o que está em jogo é a potência contra o poder, mesmo que aquela não possa avançar senão mascarada para não ser esmagada por este. (MAFFESOLI, 1998, p.70)

Baseado nesse conceito, reforçamos que nos referimos a indivíduos que se reúnem por afinidades culturais, sejam elas práticas, costumes ou linguagens em comum, mas que não necessariamente compartilham características biológicas. 
Encontra-se aqui o empreendimento mais desafiador deste ensaio: adotar uma das múltiplas conceituações de cultura. Novamente não nos atemos às incontáveis definições que os teóricos da Antropologia cunharam ao longo do desenvolvimento da ciência, este trabalho também já foi feito por Laraia. ${ }^{5}$

Preferimos tentar enunciar cultura como a entendemos: um sistema de símbolos significantes, responsável por mediar as relações entre indivíduos, entre grupos de indivíduos e entre os indivíduos e a natureza, possibilitando a esses organizar, controlar e transmitir conhecimentos a respeito dessas mediações, num processo recíproco no qual o homem transforma a cultura e é transformado por ela.

Essa concepção de cultura é claramente influenciada por autores como Geertz (1978), ainda que ele não a tenha definido com as mesmas palavras. Porém, como alguém que se aproxima teoricamente da chamada "Antropologia Interpretativa" e sua visão semiótica da cultura, abordagem na qual Geertz é um dos principais representantes, é natural que nossas concepções lhe tomassem empréstimos.

Penso na cultura como um sistema de símbolos assim como Geertz a enxerga como uma "teia de significados", e entendo que esses símbolos não possuem significados per se, mas somente à medida que lhe são atribuídos, tornando a referenciar Carneiro da Cunha (2014). Creio também que seja fundamental ao pensar a cultura, tentar compreender sua função. Geertz a aponta como um "programa" (semelhante aos utilizados em computadores), um conjunto de mecanismos de controle de que o homem precisa para ordenar seu pensamento.

Em sua função, eu a penso de maneira semelhante, como uma mediadora das relações humanas e das relações do ser humano com a natureza. Penso que a cultura funciona como mediadora dessas relações humanas, e entendo que ela modifica o indivíduo, assim como é modificada por ele. Em síntese, é uma concepção semiótica, interpretativa da cultura. E é baseado nessa concepção que pretendemos expor nossas impressões sobre os objetos da Antropologia Urbana, especificamente sobre a tatuagem e os tatuados nesse contexto.

\section{A cidade: o diálogo das múltiplas identidades}

Abordei acima o tema da diáspora e como resultado dela a adoção sistemática de sinais diacríticos por parte dos grupos étnicos, para que possamos pensar as subjetividades envolvidas na escolha que as tribos urbanas fazem de seus próprios sinais diacríticos: como esses indivíduos adotam signos de modo a afirmar sua identidade.

Carneiro da Cunha chama a atenção para "o uso de símbolos e de signos dados para promover significações novas ou não oficiais" (CARNEIRO DA CUNHA, 2014, p.239), e lembra que “... o significado de um símbolo não é intrínseco, mas função do discurso em que se encontra inserido e de sua estrutura" (CARNEIRO DA CUNHA, 2014, p.239). Desse modo, podemos pensar esses indivíduos adotando propositalmente símbolos de outros grupos distantes temporal ou espacialmente, dando-lhes novas significações nesse processo dinâmico, que é a produção cultural.

Dinâmica que não envolve apenas a cultura, que, ainda nas palavras de Carneiro da Cunha, é constantemente reinventada e investida de novos significados; a dinâmica também envolve formação da identidade do indivíduo, que pode ser observado na definição de sujeito pós-modernode Hall:

${ }^{5}$ Roque de Barros Laraia em Cultura: Um conceito antropológico discute longamente as várias definições de cultura adotadas por antropólogos de diversas vertentes. 
O sujeito, previamente vivido como tendo uma identidade unificada e estável, está se tornando fragmentado; composto não de uma única, mas de várias identidades, algumas vezes contraditórias ou não resolvidas. Correspondentemente, as identidades, que compunham as paisagens sociais "lá fora" e que asseguravam nossa conformidade subjetiva com as "necessidades" objetivas da cultura, estão entrando em colapso, como resultado de mudanças estruturais e institucionais. O próprio processo de identificação, através do qual nos projetamos em nossas identidades culturais, tornou-se mais provisório, variável e problemático. (HALL, 2014, p. 11)

Sendo estes sujeitos dotados de identidades provisórias, móveis e transitórias, valem-se dos signos e lhe atribuem novos significados conforme sua necessidade de interação ou afirmação de identidade momentânea. Essa abordagem me parece pertinente ao observarmos as especificidades daqueles a quem Maffesoli chamatribos urbanas como os punks, os clubbers, os funkeiros, os tatuados ou adeptos de modificações corporais extremas.

É importante lembrar que, na concepção de Hall, assumir uma identidade não necessariamente implica abandonar outras - "composto não de uma única, mas de várias identidades, algumas vezes contraditórias ou não resolvidas" - e, portanto, uma vez que essas identidades coexistem no sujeito, será provavelmente a relação em sociedade que influenciará na escolha da identidade adotada. Concentrando nossos esforços na pesquisa da tatuagem, tentarei, a seguir, elaborar o pensamento considerando os sujeitos tatuados.

No cotidiano das sociedades complexas, o indivíduo pode simultaneamente assumir a identidade, por exemplo, de pai, filho, médico, membro de um motoclube e participante esporádico de uma banda de música. Esse mesmo indivíduo, levando em conta uma classificação entre tatuados e não-tatuados, está inserido na primeira categoria.
A questão que se dá é que, de acordo com o papel que se espera que ele desempenhe socialmente, poderá reivindicar uma ou outra identidade: se os pais manifestam dissabores diante de sua identidade de tatuado, por exemplo, ele poderá em seu papel de filho não reivindicá-la nos almoços de família, nesse caso utilizando roupas que não revelem suas tatuagens, tendendo a agir da mesma maneira em seu papel de médico, diante de seus pacientes na rotina do consultório.

Por outro lado, nos eventos de seu hipotético motoclube ou nas confraternizações ou apresentações de sua banda de música, é provável que ele as exiba de maneira mais explícita, pois a identidade que está reivindicando ali é a de membro do clube ou de uma banda, respectivamente, sendo, por sua vez, as tatuagens, signos comuns nestes ambientes.

Desse modo, ainda que seus pacientes compartilhem o gosto por motocicletas ou que assistam à apresentação de sua banda musical, a identidade reivindicada pelo sujeito em questão tende a causar um menor estranhamento naqueles que agora assumem também tem sua identidade modificada e se tornam "audiência" no caso do concerto de música ou "irmandade" do motoclube.

No caso do nosso sujeito, as identidades são coexistentes e, em algum momento, conflitantes, sua relação familiar lhe restringe a identidade de tatuado, bem como essa identidade pode não ser socialmente apreciada quando compartilhada com a identidade de médico, assim como a identidade médica e os elementos que a compõem (jaleco, estetoscópio, roupas brancas e luvas cirúrgicas) não tendem a ser reivindicadas no momento em que o sujeito assume a identidade de membro de uma banda ou motoclube, levando-o a reivindicar uma identidade em detrimento de outra de acordo com o papel social que é esperado que ele desempenhe. 


\section{A Tatuagem: exemplos da multiplicidade identitária}

O que se tem observado, e nossos esforços de pesquisa têm-se concentrado na compreensão desse fenômeno, é que a tatuagem parece enfrentar um processo de ressignificação na sociedade brasileira, fenômeno mais notável nos centros urbanos. Os responsáveis por isso parecem ser fatores ${ }^{6}$ como o investimento dos tatuadores na criação de estúdios de aparência clínica, do papel da mídia da difusão da tatuagem e do aprimoramento da "arte" da tatuagem, conferindo aos tatuadores status de artistas e à tatuagem status de arte, parecem contribuir para esse fenômeno de ressignificação, de uma marca marginal a objeto da moda, exibido nos mais diversos corpos, em indivíduos de diversos grupos sociais.

Essa ressignificação é um fenômeno a ser estudado mais profundamente e que parece ocorrer não apenas no Brasil. No Japão, onde as tatuagens por muito tempo foram associadas à Yakuza - a máfia japonesa discussões têm sido realizadas no sentido de derrubar sanções à tatuagem, como a proibição de indivíduos tatuados em casas de banho e academias. Conforme a matéria do site japansubculture.com e sua matéria "In Japan, Tattoos Are Not Just For Yakuza Anymore 7 ", ao mesmo tempo em que leis como a do prefeito de Osaka (curiosamente filho de um chefe da Yakuza) exigem que funcionários públicos revelem se possuem ou não tatuagens. Um agente da Polícia Federal Australiana afirma que a nova geração da Yakuza é composta de cleanskins, criminosos sem tatuagens de identificação. Ao mesmo tempo, tatuadores mestres na Irezumi - técnica tradicional de tatuagem japonesa - afirmam que cresce o número de "cidadãos comuns" que buscam a tatuagem por motivos estéticos, além dos estrangeiros que vão ao Japão em busca da arte japonesa de tatuar.

No caso do Brasil, onde a marginalização da tatuagem parece ter ocorrido por questões ligadas às condições insalubres em que a tatuagem era inicialmente realizada, além do contexto histórico em que foi inserida na sociedade brasileira, considerando a classe social dos inicialmente tatuados - marinheiros, estivadores, prostitutas, trabalhadores temporários - a ressignificação parece ocorrer através da adesão de novos sujeitos à prática, levando-nos à reflexão da formação da identidade e das questões que estão em jogo nesse processo.

Um olhar atento nos permite testemunhar o surgimento de novos estúdios de tatuagem ${ }^{8}$ em considerável medida, atendendo à demanda crescente de sujeitos que aderem à prática da tatuagem.

Ao voltarmos nossa atenção aos espaços públicos, também presenciaremos a tatuagem presente em corpos diversos, em um número maior do que presenciaríamos décadas atrás. Em nossas pesquisas, tenho procurado dialogar com os sujeitos tatuados e não tatuados que pretendem adquirir sua primeira tatuagem sobre suas motivações, seus medos, expectativas. Comumente, a preocupação com o mundo do trabalho se faz presente nos aspirantes a receber sua primeira tatuagem, sendo comum o discurso da incerteza profissional como tabu, sobretudo naqueles que manifestam desejo de receber uma tatuagem, mas não o fazem.

As mudanças concernentes ao mundo do trabalho ocorridas em nossa sociedade parecem contribuir para o crescimento no número de tatuados. O surgimento de novas profissões como as áreas de Publicidade e Tecnologia de Informática (TI) - cujas empresas ten-

\footnotetext{
${ }^{6}$ Procuro seguir essas discussões mais detalhadamente em outro artigo. (SOUZA, 2014).

${ }^{7}<$ http://www.japansubculture.com/in-japan-tattoos-are-not-just-for-yakuza-anymore/> Consultado em 22 de setembro de 2015.

${ }^{8}$ Em Três Lagoas/MS, atualmente uma cidade de aproximadamente 100 mil habitantes, é possível contar ao menos oito estúdios de tatuagem com pelo menos quinze tatuadores, tendo considerável número deles surgido nos últimos cinco anos.
} 
dem a investir mais frequentemente em uma imagem de dinamismo, inovação, requisitos por vezes ligados à figura do jovem (grupo que mais frequentemente adere à tatuagem) e, portanto, mais "abertas" à diversidade e, consequentemente, à presença da tatuagem - parece ser mais um fator que contribui para a desmarginalização da tatuagem.

Porém, o que temos visto é que não somente os setores "inovadores" como também os mais "formais" têm reconsiderado suas posições com relação à tatuagem, ainda que, nesses setores, as mudanças sigam um ritmo consideravelmente mais lento. Uma matéria de $2013^{9}$ do portal de economia do site ig.com.br, cujo título é "Setores formais abrem espaço para tatuagem e outras expressões visuais", aponta para a flexibilização dos chamados códigos de vestimenta de setores como o financeiro, o direito e a área da saúde, apesar de conter nos relatos dos entrevistados, doses de cautela ao falar de uma "normalização" da tatuagem na sociedade. Em uma entrevista que realizei com o Sr. Carlos Hetch, 33 anos, vice-presidente da OAB/Subseção de Três Lagoas e advogado há onze anos, o mesmo afirma que não há restrições legais quanto à tatuagem, piercing ou outra forma de modificação corporal que impeçam o profissional de atuar ${ }^{10}$. O entrevistado acrescenta:

[...] neste tempo que em estamos na
OAB, com quase 530 advogados nenhum
caso, nenhuma reclamação nos chegou
por preconceito contra o profissional
por ter vários brincos, pulseira ou mes-
mo um piercing no nariz, e tatuagem
também não. O que pode influenciar é a
questão da contratação de um cliente
seu, que tenha preconceito. Seja pela
idade do cliente, seja por preconceito,
ou seja, por reputar isso [a tatuagem] a
uma pessoa que não esteja preparada ou
que não possa exercitar o trabalho cor-
reto. (ENTREVISTA, Carlos Hetch,
2015)

[...] neste tempo que em estamos na $O A B$, com quase 530 advogados nenhum caso, nenhuma reclamação nos chegou por preconceito contra o profissional por ter vários brincos, pulseira ou mestambém não. O que pode influenciar é a questão da contratação de um cliente seu, que tenha preconceito. Seja pela idade do cliente, seja por preconceito, ou seja, por reputar isso [a tatuagem] a uma pessoa que não esteja preparada ou que não possa exercitar o trabalho cor2015)

\footnotetext{
${ }^{9}<$ http://economia.ig.com.br/carreiras/2013-08-21/setores-formais-abrem-espaco-para-tatuagens-e-outras-expressoes-visuais.html: $>$ Consultado em 25 de setembro de 2015

${ }^{10}$ ENTREVISTA, Carlos Hetch, 2015
}

lar que possui uma tatuagem nas costas, aponta que não a fez num local visível, e afirma que, no início de sua carreira, a tatuagem não era tão "bem-vista" quanto nos tempos atuais. Porém, atualmente, na opinião dele, é incomum ouvir reclamações concernentes às inquietações quanto ao mundo do trabalho ou a dificuldade de conseguir um emprego. O que minhas conversas com tatuados e aspirantes mostram, porém, é que ainda há o receio da rejeição no mundo profissional, mas é consideravelmente menor do que fora na década passada, e isso nos permite supor uma modificação na forma como a sociedade se relaciona com a tatuagem.

Tem sido recorrente por parte dos pesquisadores da tatuagem, apontar que este caráter marginalizador sofre transformações a partir dos anos de 1970 e 1980 (MARQUES, 1997; FONSECA, 2003; FERREIRA, 2012; ALMEIDA, 2006; COSTA, 2004; LEITÃO, 2004). Porém, cabe apontarmos que os processos que envolvem transformações culturais não são, comumente, lineares e pacíficos. Para apontarmos uma ressignificação da tatuagem em contextos urbanos brasileiros, é preciso levar em conta o percurso histórico dessa transformação. Análises unicamente sincrônicas correm o risco de pecar ao ignorar tais transformações.

Neste ponto, é importante que a Antropologia se aproxime da História - e sejamos justos em reconhecer que este movimento de aproximação já ocorre há pelo menos quatro décadas - a fim de elaborar uma percepção mais complexa deusa ressignificação. Para tanto, é útil retomar uma perspectiva diacrônica que nos auxiliaria nesta compreensão.

Para Marques, a tatuagem inicia o processo de transformação de seu significado social - e cultural nos 
anos de 1970. Esse processo está intimamente ligado à adesão da tatuagem por parte dos surfistas cariocas ${ }^{11}$. Sua análise traz relatos de jornais e revistas do período, cujo retrato da tatuagem se diferencia substancialmente daqueles que vimos nos jornais do início do século XX. A tatuagem, naquele contexto, começava a marcar a pele dos jovens de classe média. Um desses jovens e seu "dragão tatuado no braço" seria eternizado na canção Menino do Rio, de Caetano Veloso. Segundo Marques, os versos da canção, que teria tocado na telenovela Água Viva, exibida na Rede Globo, teria sido o "estímulo decisivo para a classe média urbana se tatuar" (MARQUES, 1997, p. 198). Segundo ele, esse evento teria impulsionado a abertura de lojas modernas de tatuagem no Rio de Janeiro e em São Paulo, levando à profissionalização dos estúdios de que nos falará Fonseca.

Para ela, o surgimento dos estúdios é parte de um processo de institucionalização da tatuagem, pois adequaria a prática a uma série de normas jurídicas, comerciais e sanitárias, diferentemente da tatuagem praticada em lugares insalubres. Essa mudança, para a autora, estaria inserida dentro de um interesse dos tatuadores em alterar a imagem que se tinha da tatuagem até então e, consequentemente, ampliar o seu público (FONSECA, 2003, p. 26). Nesse sentido, haveria, para Fonseca, uma ressignificação da tatuagem, na qual ela passaria a ser inserida no campo da normalidade ${ }^{12}$. Essa mudança estaria condicionada à sua cooptação pelo mercado, transformando-se em mercadoria:

\footnotetext{
A normalidade a que me refiro é a da prática contemporânea da tatuagem. Uma prática que saiu da marginalidade e se introduziu num contexto mais am-
}

plo, incluindo diversos setores sociais. A partir de seu ingresso no mundo do mercado, onde se converteu em um produto de consumo, "legitimado socialmente", com base em sua nova fachada e apresentação social, que são as lojas de tatuagem, essa atividade passou a ser encarada de maneira mais profissional e artística, tornando-se parte das opções estéticas procuradas pelas novas gerações. (FONSECA, 2003, p. 10)

A transformação da tatuagem em mercadoria e sua consequente legitimação, na opinião de Fonseca, teriam efeito na percepção da sociedade quanto a ela. Estss mudanças teriam levado ao que Ferreira e Almeida chamam de "domesticação" e "abrandamento do teor subversivo" da prática, respectivamente:

A idealização de uma prática transgressora norteou muitas das minhas hipóteses iniciais, porem grande parte delas foirefutada pelo campo. Mesmo que a tatuagem tenha um longo histórico de associação com universos outlaws, presenciamos hoje uma "domesticação" do seu viéstransgressor. Tida por muito tempo como sinal por excelência da rebeldia emarginalidade, hoje a tatuagem emerge cada vez mais como uma das muitas opçõesestéticas disponíveis no "mercado das vaidades" (QUEIROZ \& OTTA, 2000), tendosido adotada por diferentes setores da sociedade, muito distantes dos ambientes demarginalidade aos quais a pratica esteve por longos anos associada. (FERREIRA, 2012, p.16)

Tais "codificações" e significados recentes do ato transgressivo apontam para as novas combinatórias surgidas entre o próprio sujeito e o abrandamento de suas preocupações em manifestar uma posição "classicamente transgressora" ou de ruptura e oposição a seu universo de valores. Refiro-me ao primado, cada vez mais inescapável, do ponto de vista estético enquanto eixo de motivações dos

\footnotetext{
${ }^{11}$ Marques desenvolve uma leitura um tanto romantizada da tatuagem brasileira. Para ele, a adesão à tatuagem por parte dos surfistas cariocas teria "redimido" a tatuagem de sua condição marginal. Não ignoramos que a prática da tatuagem por grupos heterogêneos, distintos daqueles aos quais a prática foi historicamente associada, contribuiu para a reelaboração de seu significado. Porém, é reducionista atribuir tamanha transformação cultural apenas à adesão de grupos socialmente favorecidos e sua exposição midiática. Outrossim a durante a década de 1980, a tatuagem já se disseminava por outros espaços, para além do eixo Rio-São Paulo e de uma hegemonia cultural do Rio de Janeiro.

${ }^{12} \mathrm{O}$ conceito de normalidade é pensado em oposição ao desvio, conforme Goffman (2013).
} 
sujeitos que optam pela realização da tatuagem. Isso significa dizer que a cota de tolerância e abrandamento do teor transgressivo deste ato passa por um movimento de relativização do próprio significado. (ALMEIDA, 2006, p. 144)

A afirmação de Almeida quanto ao abandono da preocupação dos tatuados em manifestar um caráter transgressor encontra alguma resistência de nossa parte. Porém, antes de propor qualquer argumentação acerca das conclusões de Almeida, é fundamental salientar que a autora enfatiza que seu trabalho não objetivava uma leitura diacrônica da tatuagem, sob uma perspectiva histórica. Tendo claro esse ponto, longe de invalidar sua argumentação, proponho-me a tentar elaborá-la a partir de dois pontos, que talvez possam contribuir para sua reflexão.

O modo como a sociedade percebeu a tatuagem até este momento parece-nos intimamente associado ao seu lugar econômico-social, mais do que apenas à sua relação direta com a criminalidade. Como aponta João do Rio, os sujeitos se tatuavam por motivos diversos: questões mítico-religiosas, amorosas, função de embelezamento ou patriotismo. $\mathrm{O}$ autor, que realizou um trabalho de cunho etnográfico ${ }^{13}$ para escrever sobre o tema, não aponta a adoção da tatuagem como a reivindicação de rebeldia, antes a relata como fruto da curiosidade, dos momentos de ócio e até mesmo influência do meio trabalhador sobre os imigrantes portugueses que chegavam ao Brasil, o que nos permite pensar a dimensão social do fenômeno naquele contexto, concomitantemente aos sentidos individuais de marcar a pe$1 \mathrm{e}^{14}$. Desse modo, não parece ter havido nesse momento, uma pretensão transgressora, no sentido de romper com as regras socialmente estabelecidas - mesmo porque o período era de extrema agitação e receptividade às mudanças, sobretudo as que vinham da Europa, o que era o caso da tatuagem.

Assim, do ponto de vista de uma análise histórica, a tatuagem teria sido, naquele contexto, investida de um caráter transgressor a partir "do olhar do outro". Se não houve por parte das classes pobres do período o intento de diferenciar-se ${ }^{15}$ - enquanto sinal identitário de classe - a partir da modificação de seus corpos, a condição de desvio ou anormalidade atribuída à tatuagem ao longo do século seria fruto da construção desse estigma por parte das camadas médias e altas da sociedade, conformando-se à teoria do comportamento desviante descrita por Goffman e Becker ${ }^{16}$.

A afirmação de Almeida acerca da existência de um caráter transgressor, porém, parece fazer sentido se tivermos em conta um período posterior, já de inserção da tatuagem nas camadas médias da sociedade. A tatuagem teria, a partir dos anos de 1970, sido adotada como uma forma de expressão por parte de alguns grupos ou "tribos urbanas", como os hippies, punks, clubbers, motociclistas, roqueiros, skinheads, rappers (LEITÃO, 2004; COSTA, 2004). Parece-nos ser em relação a estes

\footnotetext{
${ }^{13}$ João do Rio é o pseudônimo do jornalista Paulo Barreto. Tendo vivido no Rio de Janeiro no início do século XX, o autor constitui uma importante fonte para a compreensão da vida cotidiana da cidade no período. A sua riqueza como fonte se dá pela sua escrita, mas sobretudo pelo seu peculiar método de pesquisa, que envolve aquilo que poderíamos chamar de uma perspectiva "antropológica" do jornalismo - uma vez que o autor praticava aquilo que a ciência chama de "observação participante", não simplesmente visitando os espaços de produção das matérias, mas procurando em certa medida conviver e observar, mais profundamente, os hábitos dos sujeitos sobre os quais escreveria. A exemplo disso, João do Rio afirma ter passado "três longos meses" na companhia de Madruga, uma espécie de "empresário" da tatuagem, que recrutava garotos para realizar as marcações corporais no porto do Rio de Janeiro. (p.19)

${ }^{14}$ As reflexões de cunho psicanalítico acerca da tatuagem, realizadas por Pires (2005) e Costa (2014), convergem quanto a uma dupla função da modificação corporal: simultaneamente coletivizar e singularizar o sujeito, inserindo-o em um grupo enquanto diferencia-o dos demais.

${ }^{15}$ Esta hipótese não é válida se o objetivo das classes pobres, ao tatuar-se, tiver sido justamente criar um laço identitário entre si, buscando diferenciar-se das camadas economicamente favorecidas da sociedade. Porém, as fontes disponíveis até o momento não apontam para a escolha da tatuagem como sinal diacrítico, definidor da construção da diferenciação "nós x eles" por parte das classes pobres.

${ }^{16}$ Segundo os autores, o comportamento desviante não é algo produzido deliberadamente pelo sujeito, mas sim a partir dos grupos sociais que criam e estabelecem regras, cuja infração caracterizaria o desvio, marcando os desviantes como outsiders (BECKER, 2008) ou estigmatizados (GOFFMAN, 1998)
} 
sujeitos que Almeida aponta para o "abrandamento" do caráter subversivo da tatuagem contemporânea.

O segundo ponto a ser acrescentado à formulação de Almeida diz respeito à complexidade do fenômeno. E é aqui onde se entrelaçam a questão do indivíduo, presente apropriação da tatuagem como instrumento de construção identitária e como possibilidade estética; e sua relação com o outro, o processo social de aceitação ou estigmatização ao qual o indivíduo tatuado estaria sujeito.

Do ponto de vista da subjetividade, a prática da tatuagem é percebida enquanto possibilidade estética, alternativa de embelezamento, valorização de sua autoimagem, instrumento de sedução e não menos importante, apropriação sobre o próprio corpo(LEITÃO, 2004, p. 6). Retomando Stuart Hall, a construção da identidade cultural na pós-modernidade caracteriza-se pelo rompimento com as concepções de sujeito enquanto unidade indivisível, dotado de uma identidade construída em relações sólidas com as instituições e estabilizadas pelas tradições e estruturas (HALL, 2014).

Ao contrário, o sujeito pós-moderno possuiria identidades fluídas, fragmentadas e, por vezes, conflitantes. Em meio a essa complexidade, a questão da subjetividade permite ler a modificação corporal tanto como uma alternativa estética como a apropriação sobre si mesmo, frente às políticas de controle corporal socialmente impostas, que também são cambiantes e reorganizadas, possibilitando uma variação de significado da tatuagem.

Segundo Leitão, o discurso da apropriação é constante entre as mulheres por ela entrevistadas, a partir de afirmações como "o corpo é meu e faço com ele o que quero", o que parece, para ela, remeter a uma afirmação da autonomia pessoal e financeira, que autorizaria e legitimaria o controle sobre o corpo (LEITÃO,
2004, p. 7). Ferreira faz uma leitura convergente a essa, com relação ao uso político do corpo:

\begin{abstract}
Sem desprezar seu uso paraembelezamento, e reducionista acreditar que essa seja a causa única do incremento dasmulheres como público majoritário da tatuagem. As marcas corporais não refletemsomente certa individualidade como também uma procura de que esta seja exercida evivida de modo pleno diante de um contexto social que e experimentado comorestritivo. A marca envolve a mudança de status e outras situações em que se apresentaem meio a um conflito ou tensão pelo poder de modificar o próprio corpo. Há um usopolítico do corpo acenando para as relações de poder existentes no cotidiano dossujeitos, a autonomia sobre o corpo representando uma autonomia sobre o individuo. Trata-se, portanto, de uma marca que, mais que um adorno, enseja uma reflexão sobreliberdade, controle e resistência. (FERREIRA, 2012, p. 37)
\end{abstract}

Desse modo, pensar os processos de formação de identidades é obrigatoriamente pensar a complexidade envolvida neles, considerar o jogo que se desenvolve nessa formação e como o indivíduo ou o grupo lida com esse jogo, ora reivindicando uma ou outra identidade; em suma, é considerar variáveis com que o antropólogo terá de lidar. Marcus (1991) aponta que compreender a formação das identidades implica reconhecer os chamados por ele "impulsos integrativos do Estado e da economia na modernidade" quanto às "dispersões do sujeito em fragmentos sobrepostos e múltiplos de identidades". Na busca desse entendimento, ele levanta uma série de questões pertinentes:

Quais são as identidades de que aglutinam, e em quais circunstâncias? Quais se tornam definidoras e dominantes, e por quanto tempo? De que modo o jogo das conseqüencias imprevistas afeta o resultado final da fusão que dá origem à identidade diferenciada (salient) nesse espaço da construção múltipla e do controle disperso da identidade de uma pessoa ou grupo? (MARCUS, 1991, p.205) 
Responder a essas questões tem sido o desafio da etnografia, que se dedica a estudar as identidades nas sociedades urbanas, uma vez que, como dito, os processos de formação de identidades são complexos e diversificados. Questões como "Quais se tornam definidoras e dominantes, e por quanto tempo" são desafiadoras para a compreensão da identidade de tatuado e sua ocultação ou reivindicação diante da sociedade, como no exemplo hipotético de nosso sujeito citado anteriormente ou mesmo no exemplo real do entrevistado anteriormente citado.

\section{Considerações Finais}

A guisa de conclusão, este ensaio pretendeu contribuir principalmente com aqueles que se iniciam na pesquisa antropológica e têm a cidade como locus, como campo de pesquisa. Nele buscamos levantar algumas questões iniciais que nos orientem no desafio de pensar a formação das identidades nos contextos urbanos contemporâneos, onde o sujeito é simultaneamente induzido à integração e à fragmentação, como dito anteriormente referenciando Marcus, numa relação de pluralidade de influências que são recebidas pelos sujeitos, pelos mais diversos meios e que participam da complexidade da formação de suas identidades.

Retomando a introdução deste texto, que referencia alguns dos autores que pensaram esta questão, a Antropologia se vê diante do desafio de novos sujeitos, uma vez que as transformações da globalização parecem afetar todos os cantos do planeta. É preciso, porém, atentarmos para o papel desta ciência ao estudarmos as formações de identidades, sobretudo na problematização do conceito de cultura, que, ao contrário de civilização, que pode ser imposta num projeto homogeneizador, tem sido utilizada como instrumento de resis- tência de diversos grupos sociais heterogêneos, conforme Sahlins. (1997). Sendo a tatuagem o objeto de pesquisa mais habitual a nós, procuramos concentrar nossas reflexões e exemplificações nesta prática, mas creio que elass podem ser úteis ao pensarmos a Antropologia Urbana em outros aspectos, e para isso espero ter contribuído.

Para além disso, buscamos um espaço de diálogo entre a Antropologia e a História, objetivando uma análise mais ampla do fenômeno da tatuagem.

Aceitando que a noção de corpo é histórica e culturalmente construída, ele se torna um espaço político, proporcionando a relação entre sujeito e a sociedade na qual está inserido ${ }^{17}$. Nesse sentido, a pele seria um locus privilegiado de mediação, uma fronteira simbólica entre os mundos interno e externo (LEITÃO, 2007, p.8), uma borda que promoveria, por meio do contato com o outro, a constituição da identidade do sujeito. (COSTA, 2014, p.30) A partir dessa fronteira, temos o território externo ao corpo, onde se estabelecem as relações sociais. São dessas relações com o "o outro" que resulta a aceitação ou rejeição do sujeito tatuado em sociedade.

Assim, pensamos que o olhar sobre os significados da tatuagem, especificamente de sua ressignificação, como um abrandamento ou domesticação do teor subversivo, atribuído exclusivamente ao sujeito que adere à prática, caracteriza-se como uma leitura incompleta do fenômeno, uma vez que ignoraria o contexto histórico de marginalização da tatuagem e a complexidade contemporânea do fenômeno, que não envolve apenas as escolhas subjetivas do sujeito, mas também a sua recepção pela sociedade. Ou seja, uma constante e tensa negociação dos usos do próprio corpo.

\section{Fontes}

\footnotetext{
${ }^{17}$ Pires afirma que "a relação de mão dupla entre corpo e cultura sempre existiu. As formas como ambos refletem e espelham um ao outro mudam conforme as normas e os interesses da sociedade à qual pertencem" (PIRES, 2005, p.26)
} 
ENTREVISTA, Carlos Hetch (áudio). Produção: Fernando Lucas Garcia de Souza. Três Lagoas: 2015.38 min. (aprox.), 1 arquivo mp3.

STUCKY, Nathalie-Kyoko. ADELSTEIN, Jake. In Japan, Tattoos Are Not Just For Yakuza Anymore.2013. Disponível em http://www.japansubculture.com/in-japan-tattoos-are-not-just-for-yakuza-anymore/ . Acesso em 15 de setembro de 2015.

\section{Referências Bibliográficas}

ALMEIDA, Maria I. M. Nada além da epiderme: a performance romântica da tatuagem. In: BARBOSA, Lívia e CAMPBELL, Colin. Cultura, consumo e identidade. Rio de Janeiro: Editora FGV, 2006.

BARTH. Fredrik. O guru, o iniciador e outras variações antropológicas. Rio de Janeiro: Contra Capa Livraria, 2000 .

BECKER, Howard. Outsiders: Estudos da sociologia do desvio. Rio de Janeiro, Zahar, 2008.

CARNEIRO DA CUNHA, Manuela. Etnicidade: da cultura residual, mas irredutível. In: Cultura com aspas e outros ensaios. São Paulo: Cosac Naify, 2009.

COSTA, Ana. Tatuagem e Marcas Corporais: atualizações do sagrado. São Paulo: Casa do Psicólogo, 2014.

COSTA, Zélia. Do Porão ao Estúdio: Trajetórias e práticas de tatuadores e transformações nouniverso da tatuagem. Dissertação - Mestrado em Antropologia Social. Florianópolis: Universidade Federal de Santa Catarina, 2004

FERREIRA, Diego de J. V. Artesãos da Pele: aprendendo a ser tatuador. Dissertação - Mestrado em Programa de Pós-Graduação em Educação Brasileira. Universidade Federal do Ceará. Fortaleza: 2012

FONSECA, Andréa L. P. Tatuar e ser tatuado: "Etnografia da Prática Contemporânea da Tatuagem". Dissertação Mestrado em Antropologia Social - Universidade Federal de Santa Catarina, Florianópolis, 2003.

GEERTZ, Clifford. A Interpretação das Culturas.Rio de Janeiro: Zahar, 1978.

GOFFMAN, Erving. Estigma: Notas sobre a Manipulação da Identidade Deteriorada. Rio de Janeiro: Editora LTC, 1988.

HALL, Stuart. A identidade cultural na pós-modernidade. Rio de Janeiro: Lamparina, 2014.

LAPLANTINE, François. A prender Antropologia. São Paulo: Brasiliense, 2003.

LARAIA, Roque de Barros. Cultura: um conceito antropológico. Rio de Janeiro: Jorge Zahar Ed., 2001.

LEITÃO, Débora K. Mudança de significado da tatuagem contemporânea. Cadernos IHU Ideias, Ano 2, № 16. 2004.

MAFFESOLI, Michel. O Tempo das Tribos: O declínio do individualismo nas sociedades de massa. Rio de Janeiro: Forense Universitária, 1998.

MAGNANI, José G. C. A antropologia urbana e os desafios da metrópole. Tempo Social - USP. São Paulo: USP, 2003.

MARCUS, George. Identidades passadas, presentes e emergentes: requisitos para etnografias sobre a modernidade no final do século XX ao nível mundial. Revista de Antropologia 34. São Paulo: USP, 1991.

MARQUES, Toni. O Brasil Tatuado e Outros Mundos. Rio De Janeiro: Rocco, 1997.

MAUSS, Marcel. As técnicas do corpo. In: Sociologia e antropologia. São Paulo: Cosac \& Naify, 2003.

PIRES, Beatriz F. O corpo como suporte da arte: piercing, implante, escarificação, tatuagem. São Paulo: Editora SENAC São Paulo, 2005. 
RIO, João. A alma encantadora das ruas. São Paulo: Cia das Letras, 1997.

SAHLINS, Marshall. $O$ "pessimismo sentimental" e a experiência etnográfica: por que a cultura não é um "objeto" em via de extinção. Rio de Janeiro: Mana vol.3 n.1, 1997.

SEVCENKO, Nicolau. A capital irradiante: técnicas, ritmos e ritos do Rio. In: História da Vida Privada no Brasil Volume 3. NOVAIS, Fernando (coord); SEVCENKO, Nicolau (org). São Paulo: Companhia das Letras, 1998.

SOUZA, Fernando L. G. Da Margem à Moda: o processo de desmarginalização da tatuagem - um olhar a partir da prática contemporânea da tatuagem na cidade de Três Lagoas/MS. Aquidauana: UFMS/CPAQ, 2014.

VIVEIROS DE CASTRO, Eduardo. Entrevista: Eduardo Viveiros de Castro sobre Lévi-Strauss. 2011. Disponível em: <http://epifenomenos.blogspot.com.br/2011/04/entrevista-eduardo-viveiros-de-castro.html>. Acesso em 28 out. de 2015.

WAGNER, Roy. A presunção da cultura. In: A invenção da cultura. Rio de Janeiro: Cosac\&Naify, 2010 (1975).

Submissão: 10/04/2016

Aceite: $27 / 12 / 2017$ 